\title{
Article
}

\section{Participant Experience in Art-Sport: Additive? Interactive? Transformative?}

Froggett, Lynn

Available at http://clok.uclan.ac.uk/21417/

Froggett, Lynn ORCID: 0000-0001-8406-6231 (2019) Participant Experience in Art-Sport: Additive? Interactive? Transformative? Sport in Society, 22 (5). pp. 754-771. ISSN 1743-0437

It is advisable to refer to the publisher's version if you intend to cite from the work. http://dx.doi.org/10.1080/17430437.2018.1430480

For more information about UCLan's research in this area go to

http://www.uclan.ac.uk/researchgroups/ and search for <name of research Group>.

For information about Research generally at UCLan please go to http://www.uclan.ac.uk/research/

All outputs in CLoK are protected by Intellectual Property Rights law, including Copyright law. Copyright, IPR and Moral Rights for the works on this site are retained by the individual authors and/or other copyright owners. Terms and conditions for use of this material are defined in the policies page. 
Participant Experience in Art-Sport: Additive? Interactive? Transformative?

\section{lfroggett@uclan.ac.uk}

\section{Lynn Froggett \\ Professor of Psychosocial Welfare}

University of Central Lancashire

\section{Preston PR1 2HE}

\section{Acknowledgements}

The art-sport typology presented in this article has drawn on the data collected for the evaluation report of the imove programme completed by the Psychosocial Research Unit at the University of Central Lancashire. Thanks are due to Alastair Roy, Julian Manley and Suzanne Hacking for their role in that work, and to Lizzie Muller and Jill Bennett at the University of New South Wales for discussions on audience engagement and third space in trans-disciplinary fields. 
Participant Experience in Art-Sport: Additive? Interactive? Transformative?

\begin{abstract}
imove, which became Yorkshire and Humberside's regional programme for the 2012

Cultural Olympiad, was inspired by 'the art of movement', and underpinned by the idea of transcending dualities of mind/body and art/sport. Art and sport were combined in various ways within the programme, and with different degrees and types of audience engagement and participation. This article draws on the evaluation data collected during the course of the programme to develop a typology of art-sport relationships: additive, interactive, and transformative. It defines and illustrates each instance with examples of particular projects
\end{abstract}


and highlights the role of the participants/audience in determining the nature of the physical learning and new knowledge of the moving body that arises in each case. Finally, it considers the conditions under which hybrid forms of art-sport can innovate and flourish with reference to the concept of 'third space'.

Keywords: art-sport, participation, transformative, instrumental, intrinsic, third space

\section{Introduction}

Do the changing conditions under which contemporary art and sport are practised favour a closer relationship between the two? Welsch (2006) identifies an aspect of contemporary culture which does in fact appear to facilitate a convergence: specifically the aestheticisation of everyday social practices which has arguably contributed to the blurring of the boundaries between 'high' and 'low' art. Welsch's claim is that both art and sport can be transformative for spectators or participants in comparable ways. There has been an episodic discussion, especially in the fields of philosophy of sport and aesthetics, on whether sport can legitimately be regarded as art (for example Best 1974, 1980, Werz 1986). The questions that concern us here are what hybrid forms can the interaction between art and sport take? How do they implicate audiences and participants in their development, and with what impacts on individuals and communities? Under what conditions can 'art-sport' flourish?

This question is addressed here by developing a typology of art-sport interaction. For purposes of illustration it takes examples from a single programme, imove - which combined art and sport in a number of different ways, and which became part of the Cultural Olympiad programme for Yorkshire and Humberside. The Psychosocial Research Unit at the University 
of Central Lancashire conducted a two-year evaluation of this programme (Froggett et al 2013). The purpose of the present article is not to reprise the evidence for imove's achievements or shortcomings' but to think beyond the documented outcomes of the evaluation in order to produce a conceptual model of art-sport interaction. After the Cultural Olympiad, imove continued to support key projects that had demonstrated sustainability and was re-constituted as imove arts $^{2}$. These projects are of interest by virtue of the fact that they continued to attract audiences, participants, funding and community profile long after the conclusion of the original imove programme, and therefore at the very least they afford localised examples of viable art-sport projects. Two of them: Runs on the Board and Sea Swim inform the model developed here.

Over a two-year period imove commissioned a range of projects inspired by 'the art of human movement'. The aims for the programme were ambitious and a strong accent on participation was central to their realisation. From the outset people of the region were to be introduced to new cultural experiences in which physical learning and awareness of the moving body would follow from combinations of sport and arts based activities. It was intended that community and identity would be built through enhanced health and well-being and through the positive regional self-perception and regard that an enriched cultural offer could support. It was hoped that wider national and international links would follow, but more importantly that culture would be repositioned as central and relevant to people's lives by drawing on and enhancing existing regional resources (especially in terms of sporting activities) and strengths.

\footnotetext{
1 The original report can be found at http://clok.uclan.ac.uk/19648/1/imoveFINAL_WORD_300713_071013.pdf

2 imove Arts website https://www.imovearts.co.uk
} 


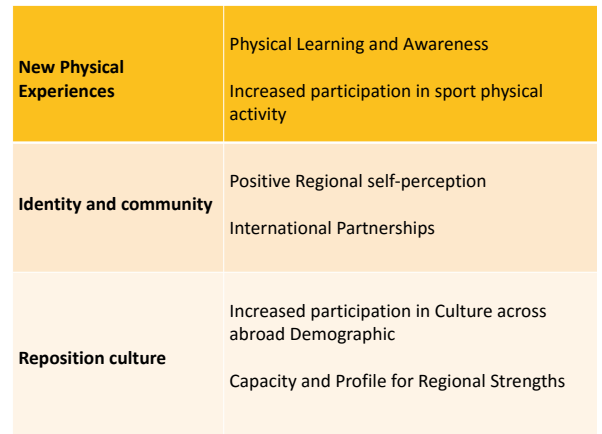

Figure 1. imove's key aims.

The programme commissions were very diverse in terms scale, target audience, how they built on sporting and cultural traditions, and the use they made of urban spaces, landscapes and the coastline of the region. Most projects were arts led but involved sport in varying degrees. Examples were: Runs on the Board, the over 50's Grey Fox Trophy cricket series, with artists and writers working alongside the game and producing work inspired by it; Phoenix Theatre's Score and Dancing with Rhinos where the dance moves were inspired by football and rugby; Games in the Park which was aimed at children and young people in Bradford; Stanza Stones which combined walking with poetry in a contemplative exploration of nature, led by poet, Simon Armitage; Synchronised which fused synchronised swimming and classical Indian dance in both performance and participatory Aqua Kathak workshops; Cycle Song a participatory operatic spectacle in Scunthorpe, based on a local cycling hero; Sea Swim in Scarborough where open water swimming continues to inspire a range of associated cultural activities. 
The Psychosocial Research Unit at University of Central Lancashire became the research partner for the imove programme in its delivery phase, with a brief to evaluate psychosocial outcomes for individuals, groups, communities, and the cultural sector. The complexity and diversity of the imove programme meant that a variety of research strategies were needed to capture process and outcomes at personal, project and programme level and these had to adapt to different forms of activity and event as the programme unfolded. Methods were ethnographic, narrative, observational, interview and survey-based, and they were used in combination in in-depth case-studies, extensive rapid capture surveys, and for programme overview. Much of the final report considers what imove achieved for participants, host communities and partner organisations (Froggett et al 2013). However, at the heart of the programme lay a complex issue that can now be re-considered with hindsight: the relationship between physical movement, especially in its sporting forms, and art.

The Programme Director, Tessa Gordzeijko, came from a predominantly arts background with a strong interest in dance, but was also prepared to take seriously and re-articulate for a contemporary regional context elements of Pierre de Coubertain's vision of Olympism (2000). In the idiom of his time (1863-1937) de Coubertain promoted the idea of combining in a balanced whole exalted qualities of body and mind, through involvement in the Games. The Cultural Oympiad in its original conception was to provide an artistic avenue for the expression of the Olympic spirit. It is fair to say that it has had a chequered history, variously attributed to the overtones of a now dated Nietzschean vitalism; de Coubertain's admiration for British public school education (1988); distaste among artists for ferocious public competition; and the fact that sport per se has proved to be a somewhat restrictive subject for art. The 2012 UK Cultural Olympiad was less concerned with Olympian competitive ideals than with offering an ambitious and diverse cultural programme in parallel with the Games 
(Garcia, 2012). Among other opportunities, this afforded regional arts organizations access to funding that could be used to raise public awareness and interest in the relation between sport and culture. The Legacy Trust UK allocated $£ 24$ million to 12 programmes across the UK regions with the following explicit aims:

- to unite culture, sport, knowledge and learning, in line with the values and vision of the Olympics

- to make a lasting difference to all those involved

- to be grassroots projects, often small in scale, and uniting communities of interest at local and regional level. ${ }^{3}$

Gordzeijko's intention was to bring a clear philosophical perspective to the task of putting together a regionally relevant programme that would achieve these goals. In particular, she saw the opportunity to use human movement in its many forms to challenge Cartesian dualism - which she associated with the mind-body split endemic in Western culture. Cartesian dualism can be linked to low rates of participation in art and sporting activities alike, insofar as it supports a reductionist view of sport as a 'merely' physical activity and an elitist view of art as a 'cerebral' form of expression, accessible to the highly educated. The particularly low participation rates for physical activity in the Yorkshire and Humber region could be linked to deficits in health and well-being at a population level. By combining art and sport in new ways around the possibilities of the moving body, imove intended to ride the wave of interest in sport generated by the Olympics. It aimed to commission movement based art, not only for known venues and audiences, but for communities in areas where cultural investment had been historically low. The notion of human movement was intentionally

3 https://culturalolympiad.wordpress.com/2012/05/17/the-legacy-trust-their-regional-programmes/ (accessed 22-08-17) 
expansive so that the programme could draw on the diversity of cities of inward migration, such as Bradford, showing how it has been enriched by population flows, as well as settled, traditional white communities, and the skills of organisations that made up the cultural sector itself. imove was, among other things, an identity project, with a strong commitment to the healthy body in movement at its core and an implicit conviction that this was a goal around which people could unite.

Despite the strong intellectual underpinnings and coherent sense of purpose with which the programme set out, the imove vision proved hard to distil into simple messaging that the public could readily comprehend. The concept of mind/body integration has been promoted by popular 'wellness' psychology, and esoteric practices such as yoga, but the experience of the programme suggests it still has little local and regional purchase, at least in Yorkshire. Confusion as to what it might mean in the context of imove seemed to accumulate as activities gathered pace. Attempts were made to clarify the idea for the purposes of marketing but the problem appeared to be that in drawing on a philosophical framework which offered a challenge to habitual ways of thinking and commissioning hybrid art-sport projects that were themselves unfamiliar, imove was unintentionally surrounding the problem of mind/body and art/sport with an aura of 'strangeness'. This compounded the split that it sought to overcome. Members of the public who were interviewed declared that they didn't have a clue what it was about, while the marketing consultants urged a simpler and more straightforward message. Gordzeijko referred to the problem of being dogged by the purity of the concept. As a result, messaging was simplified without, however, abandoning the core idea which continued to inform the more complex projects. Art-sport and mind-body relations, if they were to be worked through in the context of imove, would have to find practical expression in the activities themselves where they could then more easily be recognised. However, the 
problem of conceptualising the different ways in which art and sport can in principle combine, remains. Art-sport projects within the imove programme suggest a typology that could be heuristically useful in identifying the underpinning modes of public engagement and participation.

With hindsight, and through examining its different expressions, a tripartite model has emerged that characterizes the forms taken by art-sport within the programme: additive, interactive, transformative. This model is here illustrated through projects that are instances of the combinations it describes. The discussion that follows the presentation of empirical examples will help to clarify the conditions of third space under which art and sport interact to produce transformative effects.

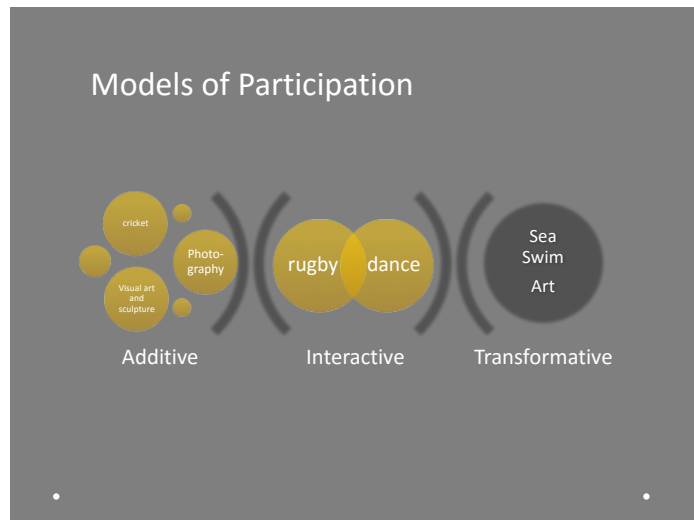

Figure 2. Art-Sport: Additive? Interactive? Transformative?

\section{Theoretical framework}


The theoretical framework that informs this typology draws on a psychosocial conceptualisation of third space as an 'in-between' arena of experience (Winnicott 1971) that arises at the boundaries of what is subjectively known but has yet to find a symbolic form that allows it to be shared with and communicated to others. This is the ground on which the unknown, which can be perceived as either full of potential, or threatening and alien, can be encountered without preconceptions, and therefore with curiosity and openness to discovery. It is essentially a ludic space favourable to emergence insofar as it allows for the suspension of habitual and taken-for-granted assumptions about the nature of play, games and other forms of creative activity, and the rules by which they are bound. From a developmental perspective Donald Winnicott ([1971] 2005) who designates it 'potential space' saw it as the locus of creative exploration of the world, where subjective experience finds expression in shared cultural form. Third space or potential space is 'in-between' in the sense that it is a third area of experiencing, neither wholly subjectively conceived, nor wholly objectively perceived, and the originary location of culture. The capacity to make use of the space of cultural experience is elaborated throughout life in the reception and production of art, literature, sport and other cultural forms.

Psychoanalyst Christopher Bollas (1992) argues that self-expression within cultural domains, as well as in everyday life, allows for the refinement of personal idiom. Hence selection, participation and performance in art and sport can be regarded as expressions of personal idiom in a cultural form. Philosopher of art and music Suzanne Langer ([1942] 1990) argues that the symbolic activity at issue here is 'presentational' rather than 'discursive' and represents the articulation of knowledge as sensuous bodily practices, for the most part unavailable to verbal language. German cultural analyst Alfred Lorenzer (1986) regards this as the basis of sensuous symbolic 'scenic' experience that accounts for the vitality of cultural 
expression. His work, from a very different, depth hermeneutic, intellectual tradition, converges with that of Winnicott on identifying the in-between nature of cultural experience, and Lorenzer comments on the compatibility of Winnicott's concepts with his own theory of ‘symbolic interaction forms' (Lorenzer and Oban 1978). Elsewhere in the context of sci-art I have argued that the concept of third space is useful in understanding what happens when knowledge is produced in the encounter between disciplines, where there is as yet no settled discourse (Muller et al 2015, 2018).

Together with colleagues in the Psychosocial Research Unit at Uclan and in the arts sector, I have developed a new group based methodology, the Visual Matrix, based on the principle that in order to understand a third space in any given context, we have to create one under carefully curated conditions (Froggett et al 2015). This development occurred subsequent to the imove programme evaluation which, however, clearly revealed the methodological gap that it responds to. I shall refer to this again in the discussion and conclusions, though a full exposition of the methodology is beyond the scope of this article. I have also attempted to demonstrate that third space facilitates expressions where the aesthetic dimension of experience comes strongly to the fore as an 'aesthetic third' (Froggett and Trustram 2014) and that this accounts in part for the distinctively new knowledge that arises within it, and its transformative potentials. In the typology presented here the transformative model both requires and reproduces third space more consistently than the other two, although it is likely to arise provisionally and often with productive instabilities in all three instances. I shall attempt to show by means of examples, how art-sport in third space is likely to be characterised by a distinctive aesthetic, that defines it as a new, hybrid, transdisciplinary practice. 


\section{Additive Art-Sport}

Runs on the Board was a classic example of an 'additive' case where Art and Sport illustrate or interpret one another, but where each retains distinctiveness as a cultural form. The project featured a cricket series for teams with a combined age of over 550 and culminated in the award of the 'coveted' Grey Fox Trophy, a glass sculpture of a victoria sandwich cake, at the Headingley Carnegie cricket ground in Leeds. The trophy was designed by The Curious Guide artists Rob Young and Tim Sutton and set the tone of the accompanying mobile installation. Over-fifty's cricket was rescued from nostalgia by a note of affectionate irony and self-deprecation in the art that graced the display cases, featuring, for example, the iconic 'Man of the Match' prize, The Combover Ball

Figure 3. Man of the Match Trophy Photograph by Anton Want
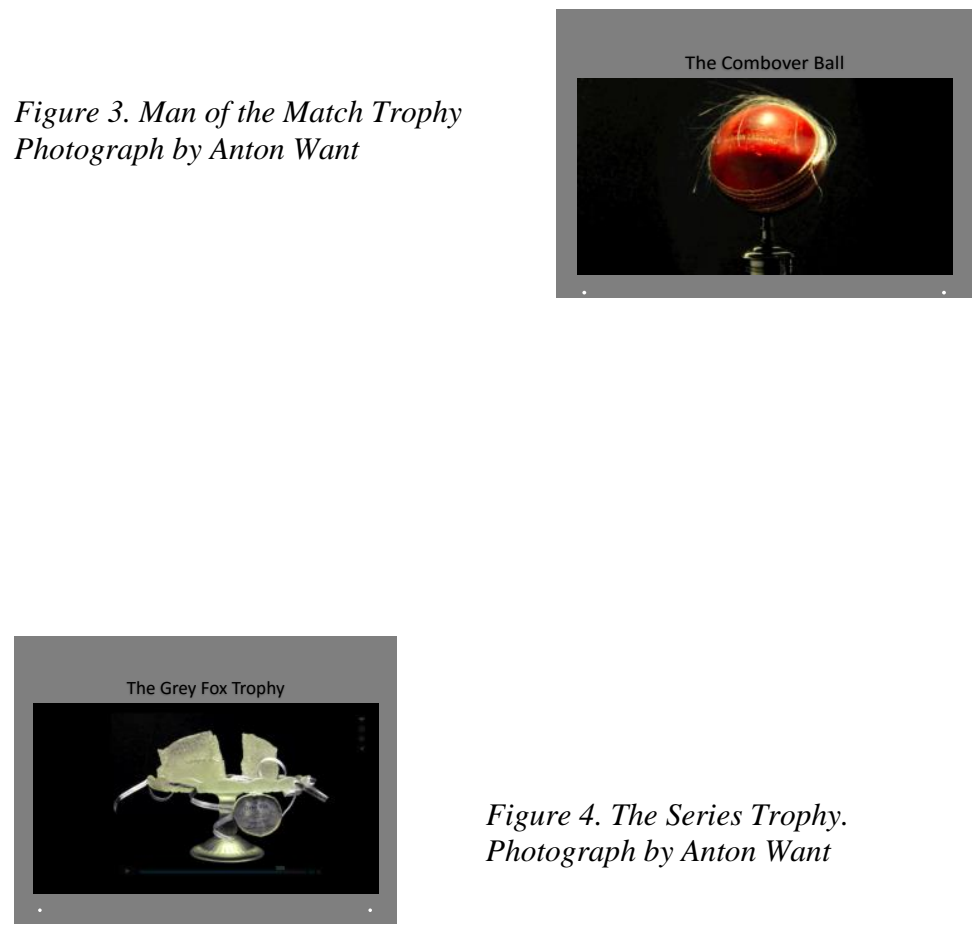

Figure 4. The Series Trophy.

Photograph by Anton Want 
On a classical note, there was a limited edition hard copy book edited by Graham Roberts (2011) with poet Andrew McMillan and photographer Anton Want who attended dozens of local matches around Yorkshire, capturing the spirit, personality and aesthetic of game and its amateur older players. Portraits were accompanied by photographs celebrating scenes of pitch, figures and sky against cricket green and conversations recorded through a poet's ear.

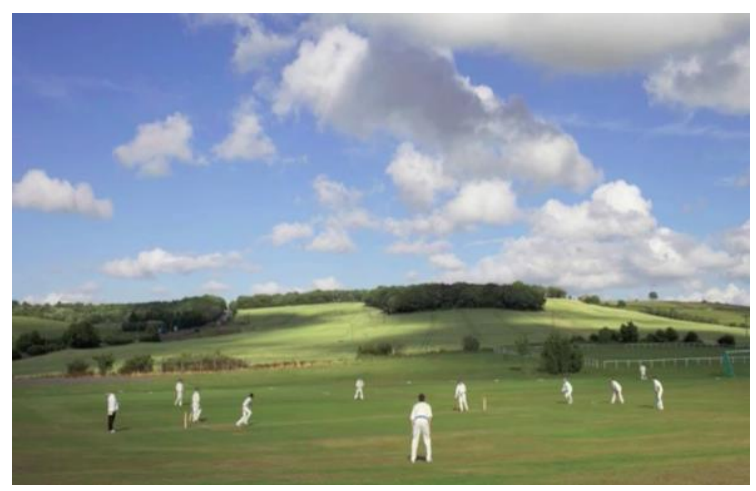

Figure 5. Image from imove touring installation. Photograph by Anton Want

Amateur cricket is woven into the warp and weft of Yorkshire life and local matches are social affairs. Audiences for the matches were diverse, as the sport attracts an enthusiastic South Asian following, whose experience of cricket may be less steeped in the aesthetic of Englishness that inspired much of the work on show. However, the additive model meant that 
the art and the cricket could in principle be enjoyed for their mutual enhancement, or separately from one another. The centrepiece and inspiration for the whole project undoubtedly remained the cricket itself, with the artwork as something of an embellishment; delightful and amusing to those for whom it was meaningful, but not indispensable to the Runs on the Board experience. This is not to gainsay the pleasure that the art afforded to those who engaged with it. In several short interviews conducted at the ground it consistently attracted curiosity and favourable comment. It could well be argued that the 'parallel' existence afforded by the additive model gives maximum freedom to both the art and the sport since neither is constrained or qualified by the other. Members of the audience are at liberty to bestow their attention selectively according to taste and disposition. However, beyond individual preferences, the art aimed to expand the symbolic registers available for the game capturing the distinctive and elusive quality of events aimed at older players and their communities along with their good humour, sociability, localism and timeless devotion to the sport, where at a local level competitive success is regarded as secondary to love of the game for its own sake. Although not its primary purpose, the art aimed to find a form for these qualities that also enhanced marketing of the series. A measure of success, and the affection bestowed on the project, is the ongoing sponsorship that has allowed it to continue each summer, ensuring a lasting legacy.

\section{Interactive Art-sport}

imove also commissioned a series of projects in which there was a more interactive relationship between art and sport in the sense that they combined to produce something genuinely novel which would not have existed except through this engagement. The mutual influence of art and sport in such instances occurs in settings where one is transposed into the other; usually, sport becomes the subject matter of participatory arts (rather than vice versa). 
Reflecting the Legacy Trust's commitment to 'Artists Taking the Lead' the interaction in the imove projects was arts-led. This is unsurprising in the sense that artists are professionally concerned with transgressing boundaries, exploring the as yet unrealised potentials of their materials, and confounding expectations. In this model the audience may either enjoy the outcome of the art-sport interaction, or become more actively involved in its processes.

\section{In the Blink of an Eye}

As an example of the former relation, imove supported the commissioning of two artworks for the exhibition at the National Science and Media Museum In the Blink of an Eye. Forms by Quayola and Memo Akten was based on digital analysis of the body in motion, in successive phases, as athletes push themselves to extremes of performance. The resulting forms are kinetic abstracts - volumetric sculptures of the relation between pure movement and surrounding element ${ }^{4}$. In this case the art-sport relationship is essential to the outcome, each being dependent on the other, and the audience is presented with a finished product, which by virtue of its scale and presence in a gallery setting is able to offer a vicarious experience to the spectator who, however, is incidental to the finished work.

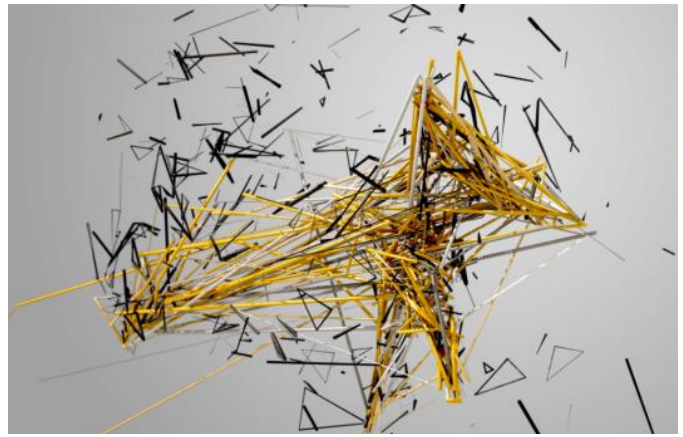

Figure 6. Still Image from Forms Artists: Quayola and Memo Atken, Science and Media Museum https://www.scienceandmediamuseum.org.uk/what

\footnotetext{
${ }^{4}$ Some of these can be viewed on vimeo at https://www.scienceandmediamuseum.org.uk/what-was-on/blink-
} eye\#\&gid=1\&pid=1 (accessed 20-08-17) 


\section{Dancing on Together}

Dancing on Together effected a more participatory combination. Sharon Watson, Creative Director of Phoenix Dance Theatre, choreographed Score and Dancing with Rhinos, modelled on football and rugby moves respectively, and performed to enthusiastic young audiences at Leeds United FC and Headingley Carnegie Stadium. In the course of the programme, opportunities arose for young people from local schools and clubs, many of whom had no previous dance experience, but who would have been familiar with rugby and football, at least as spectator sports. Charis Charles, education co-ordinator for Phoenix was surprised by the impact on young people of performing in front of large crowds of sports fans

... we didn't know how the audience was going to react and I prepped them, you know, one of them was as young as $13 \ldots$ how do you prep a 13 year-old that you might, by over 10,000 people, potentially be booed off? ... They were on the big screens, it was such an occasion and the audience response couldn't have been better ... that is just sports audience seeing, you know, live art ... (Charis Charles 13.07.12)

Community sport development officers from Leeds United supported the event with balls, flags, whistles and markers, so that at a community level barriers between the worlds of dance and sport began to be dismantled. The same was true of the gender divisions between dance and these overwhelmingly male dominated sports.

At an individual level the dance was enjoyed by young people who would normally have been excluded by fiercely competitive team sports, raising self-esteem. For example, in the case of one boy 
I've just watched him perform a dance piece in time, catching a ball and actually lead the steps, you know, I've never heard of that being achieved and I've got my son to prove it and actually he was told he would never do this... (Sharon Watson 13.07.12)

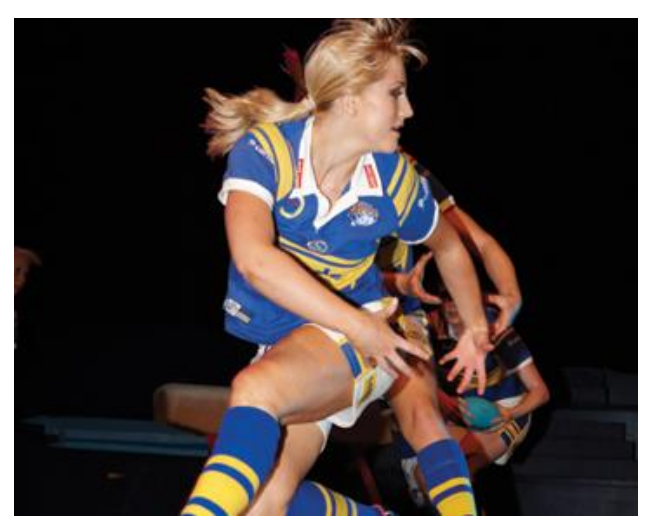

Figure 7. Dancing with Rhinos

This interactive model realises its full impact through participation. Given the status of football and rugby in these Northern English communities sport-themed dance would most likely have been of interest, even if performed solely by professionals, however the opportunity for young people to practise it raised enthusiasm for contemporary dance to a new level, while at the same time deepening public understanding of grace and choreography within the sports themselves. In this sense, the project was educational without being didactic, developing authentically new forms of self-expression and public appreciation of movement.

\section{Transformative art-sport}

The interactive mode is unstable in the positive sense that it opens the door to fuller more 
diverse and self-sustaining public engagement and therefore something enduringly transformative. Transformative art-sport is likely to depend both on a professional input that transmits key skills, ambition and confidence, while developing completely new cultural forms that depend for their realisation on the full contribution of participants. The impacts are likely to be complex with the potential to bring about profound shifts in sensibility for individuals and communities, while the art and the sport are each expressed through the medium of the other and the environment in which they occur, to the extent that it is no longer possible to 'weigh' or 'disentangle' their respective contributions.

Sea Swim

Sea Swim is about process: documentation and display; sub-cultures; the movement from sensation to narrative; suspension to weight; the embodied imagination - the sea is the ultimate liminal space and Sea Swim moves back and forth between the sea and art. (Sea Swim website 22-08-17)

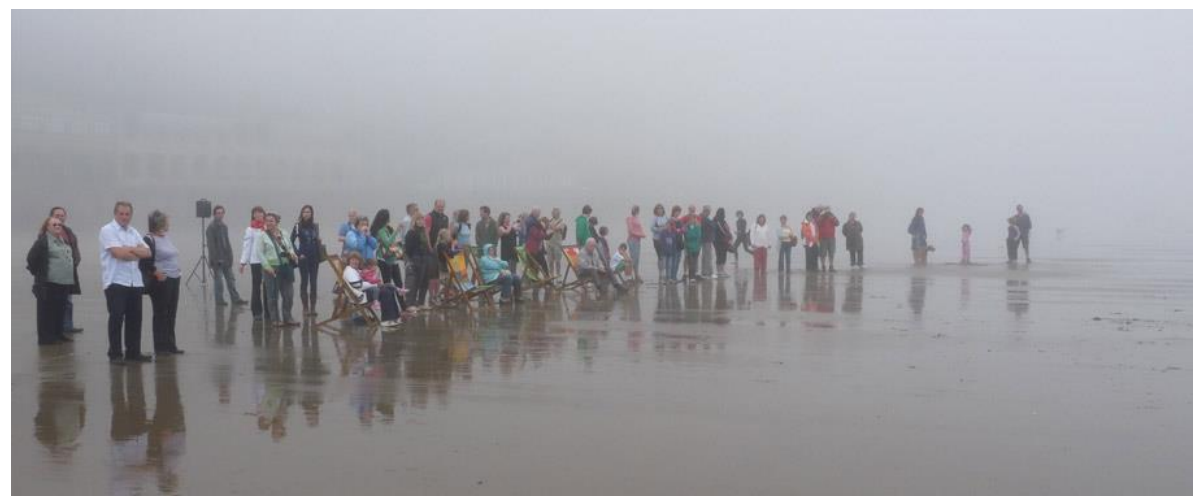

5 http://Sea Swim.co.uk/exhibitions/ 
Figure 8. Sea Swimmers and Supporters

The Sea Swim project in Scarborough ran from May 2011 to September 2012 and was codirected by artist, curator and swimmer, Lara Goodband, with poet and swimmer, John Wedgwood. It proved so popular that it gained ongoing support from imove, Legacy Trust UK and Arts Council England, and continues as an open (very cold) water swimming club with an intrinsically cultural dimension. The project took inspiration from the fortitude of generations of cold water swimmers whose legacy is remembered in Scarborough through the organized forms it has taken, and through ancestral figures whose stories have passed into local family folklore.

The physical focus of the activities was where land and sea meet in the wet sands and chilly waters of England's North Sea shoreline. Equally indispensable, as a site of preparation, recuperation and sociability, were the two adjacent Edwardian bathing huts where poetry was read and written and where blue shivering flesh turned vibrant pink over hot tea, homemade cake and conversation. According to eight of the swimmers interviewed directly after a swim heightened sensation led naturally to creative self-expression, and this was visibly reflected in the comments, sketches and fragments of poetry pinned to the walls of the hut.

By infusing sea swimming with imove's commitment to the idea of body/mind integration, or embodied mind, and linking it to historical traditions, a sense of place, home and culture became integral to the experience. The basis, however, was the existential awareness that arises in startling liquid sensation and the exploration of separation, connection and borderline between terrestrial and aquatic perception

There's something about...the way in which the water finds out every single part of 
your body ... You know where you are, you're not in some virtual world anymore, you're back right in your body... I'm kind of interested in those moments of transition from being on dry land to being buoyant and out in the sea...and the stories that have grown up out of that very simple experiential change of weight from the land to the sea ... a whole host of Mediterranean literature based on sea journeys, and I thought wouldn't it be great if we start with the actual experience of going in the sea and then build out of that towards stories that exist around that very basic experience, body experience, being in water. (John Wedgwood Clarke, Sea Swim Artistic Co-Director, 07.07.12)

Openness, that infinity, that looking in one direction and seeing nothing and in the other direction and seeing the land and being anchored. To me it's all about... all the experience is about that sense of separation from the land. (Sea Swimmer, quoted in Damian Murphy's Sea Swim podcast ${ }^{6}$ )

The altered perspective, achieved through bodily experience in the present, found expression through the conversational exchanges of the group and was the most important outcome for individuals. It was directed simultaneously 'inwards' in self-reflection and 'outwards' towards a shared sensibility expressed in poetry and art, This was confirmed in our interviews and in public statements as swimmers gained heightened consciousness of self, environment and other people

When you get out into the sea you have a completely different take on the place that you spend most of your time... (Sea Swimmer in Damian Murphy’s Sea Swim podcast) 
When the sun's out, it's just absolutely amazing, just watching, watching the reflections on the surface of the water and I definitely am more appreciative of living here now. (Sea Swimmer in Damian Murphy’s Sea Swim podcast)

I have found that the beach and the sea form a greater part of my idea of home than I'd realized. (Sea Swimmer in Sea Swim self-evaluation, 25.10.12)

As my head slips under the glass-like surface I think of friends, of family, of those who are far from me - yet we are all connected by the tide of water and time. (Sea Swimmer in Sea Swim self-evaluation, 25.10.12)

Finding shared artistic expression allowed the group to make full use of the swimming as a sensory and reflective experience. Swims - always in a group - would often begin by sharing a reading from Homer's Odyssey. Swimmers took these words with them into the water where they remained present in their minds and bodies, were 'salted' with the sea and emerged to be woven into new thoughts, stories, prose and poetry. These were recorded on post-cards, diary notes and sketches pinned to the beach-hut walls and some found their way into exhibits in the Scarborough Art Gallery in a show that included visual art, film and creative writing. The exhibition extended the presence of the project within the town and expanded its reach to visitor audiences. Variants of it travelled regionally to York and Middlesborough Institute of Modern Arts (MIMA). Wedgwood Clarke compiled and performed A Swimmers' Manifesto. Swimmers' reflections attested to sensory transformations, sociability and dramatically improved sense of wellbeing, recorded in podcast by sound artist Damian Murphy ${ }^{7}$, in creative writing by swimmers themselves, and in an anthology by Wedgewood Clarke (2014).

${ }^{7}$ http://www-users.york.ac.uk/ dtm3/practice.html 
We emerged from the sea as Odysseus did - but laughing at the nebulas of swirling mist that danced with us...No eagles, but distant gulls, as we stroked along, mammals in our element.' (Sea Swimmer's postcard, Sea Swim exhibition at MIMA)

However, the perceptual acuity that followed from each swim could take poetic cues from observed banalities of situation, as well as high art.

Spilt sugar as action art; tea bags dropped on the concrete a gesture testing the immanent weight of saturated tea leaves - soft land art. (John Wedgwood Clarke, extracts from 'Splash. Towards a Swimmer's Manifesto')

Seventy-four seconds (by John Wedgwood Clarke and Lara Goodband, with a sound track in response to the film by Damian Murphy) was a digital installation taking up a large selfcontained room. The film, shot at nose level of a swimmer while treading water, was projected along an entire wall, accompanied by sounds of the sea. The enveloping sensation allowed viewers an intimate sensation of swimmers floating in water and of the sea's movement, blueness and hypnotic musicality. This translation and mediation of movement through water aimed to help the audience, even if they were not sea swimmers themselves, to grasp the distinctive aesthetic of the experience.

Sea Swim's impact in the town depended on a significant set of local partnerships with the Local Authority, schools and community outreach and educational programmes.

Surprisingly, it became clear the beach was for many people an underused and undiscovered resource, even for children who lived in the Scarborough coastal area. The project was also able to draw in the Stephen Joseph Theatre which transported dance out of the studio and onto the shoreline for a performance of Ballet Boys on the Beach. ${ }^{8}$

\footnotetext{
8 Ballet Boys at Sea Swim You Tube. Published 10-07-2012 https://www.youtube.com/watch?v=X_bZI7imPmM (accessed 22-08-17)
} 
In summary, Sea Swim helped to realize a number of imove's key aims of transcending divisions between sport and culture. 'The artists have been brought to the water and the swimmers to art', (Lara Goodband 18.08.12). There is abundant testimony from the swimmers themselves that the experience was personally transformative in building physical and artistic confidence and encouraging people to do things they never expected of themselves. Among the changes wrought was an ability to see Scarborough itself in a new light, to appreciate how a particular relation between land and sea was intrinsic to the sight, sound, feel and temperature of the place. Sea Swim achieved this by articulating a distinctive relationship between body, mind and place produced by its activities.

\section{Discussion}

\section{Instrumental and Intrinsic Art-Sport Values}

There is a risk in describing art-sport interaction and transformation of focussing primarily on instrumental outcomes since these are most likely to support self-advocacy where funding is at stake. An important aspect of imove's pitch rested on the health and wellbeing that increased involvement in sport and other forms of movement could bring to individuals. Another strong suit, played to gain the support of financially beleaguered local authorities, was the potential of imove projects to bring together communities, offering activities to a range of demographics and abilities, and building a sense of connection and ownership of local environments and their resources, as well as strengthening the visitor economy.

It had to be sold on the wider benefits, i.e. using arts and swimming as the tool for economic/social benefits and potential for raising awareness as a visitor destination... the potential of the project having national status through imove rather than the artistic concept. (Rowena Marsden, Culture Events and Film Officer, Scarborough Borough Council 28.11.12) 
There has been animated debate within the cultural sector on the distinction between instrumental and intrinsic values (Holden, 2004, 2006). The arts sector has been, and remains, deeply mistrustful of the instrumentalism originally ushered in with New Labour's cultural policy and which has remained a key driver of DCMS ${ }^{9}$ investment (O’Brien 2013). The AHRC's cultural value programme report (Crossick and Kaszynska, 2016) attempted to move the debate beyond what it saw as a simplistic dichotomy, and many would now accept that intrinsic value is in any case vital for the realisation of instrumental outcomes.

Gordzeijko (2013) has made the same case with respect to imove. The examples in the tripartite model outlined above suggest that the argument holds in art-sport of whatever kind. Runs on the Board has only been sustainable to the extent that it provided excellent and meaningful entertainment to the communities from which the players came, and who were the audience and support base for the project. The series gave expression to an embedded amateur sporting tradition and an enduring local passion. In the blink of an eye provided visual analysis that enhanced understanding of the athletic body at extremes of performance, but it depended for its impact on the visual/kinaesthetic abstractions that formed arresting artworks in themselves. The Dancing on Together projects enhanced appreciation of rugby and football moves, and expanded the range of opportunities available to local youth, not simply through an act of translation (sport to dance) but through an imaginative elaboration of an embodied intelligence that the art and sport held common, and that could be represented choreographically. In the transformative model we see an even closer alignment between the intrinsic quality of the experience of cold open water swimming as a participatory art-sport form and its health and community benefits. However, it was only in and through the cultural forms that swimmers found to express their experience that the mind-body integration took full effect and became available to thought and representation. The wellbeing induced was

\footnotetext{
${ }^{9}$ Department of Digital, Culture, Media and Sport
} 
then felt in the body, registered in the mind, and expanded in the imagination into something that was both intimately personal, and yet at the same time cultural - which is to say it could be the object of a shared and communicable experience. This is likely to have been the basis for its health effects, which were both mental and physical, and also for its potential to enable new forms of community inclusion and solidarity.

\section{Innovative participatory practices and new methods}

It should be clear then that the audience/public are far from being incidental bystanders to artsport. They are in the position of being not only recipients but active interpreters of these new and inherently 'unstable', or evolving, hybrid forms. The instability is inevitable to the extent that these are emergent practices that cannot be located in a particular cultural discipline, or governed by an established set of rules. There is a danger that in developing a heuristic model which attempts to define possible combinations of art and sport, practices that are still developing become artificially categorized and thereby fixed. Instability is desirable to the extent that it allows an open field of innovation but experimental practices still have to attract resources to develop. As the Fields of Vision Manifesto ${ }^{10}$ observes there has been little cultural investment in art-sport, as compared to Sci-Art, for example. The latter has gained significant funding, and has prestigious peer reviewed publication platforms. Sci-art has succeeded in becoming a distinct field of both practice and transdisciplinary scholarship. Artsport carries no such recognition, although a discussion of 'sport as art' has surfaced in various literary and philosophical debates (Wertz (1985 [2012]). Wertz is one among several

\footnotetext{
${ }^{10}$ Fields of Vision: a Manifesto for the Arts and Sport Together https://artsinsport.wordpress.com/a-manifesto-for-the-arts-and-sporttogether/ (accessed 23-08-17)
} 
critics of David Best's argument that sport cannot be considered an artform because, although sport as a practice certainly has an aesthetic dimension, it does not accommodate expression of meaningful life issues (Best 1974, 1980). Although this discussion might still hold some interest, it is of limited use in building a field based on the aesthetics or art of movement that will attract public support. The study of art-sport needs, at the very least, to map or conceptualize the possible relationships at stake in order to produce strategies of engagement and a convincing account of where the public benefit might lie, and this might also shed light on the 'life issues' that gain expression through these forms of physical and cultural activity.

This article attempts to take a step in that direction, and in so doing argues that the public should be brought into the equation and that this implies a consideration of the conditions under which art-sport is produced, and very possibly a new set of methods with which to capture what is effectively a tri-partite rather than a dualistic relationship, in which audience or participant experience is key. The virtue of considering the transformative model in some detail is not that is in some way superior to the interactive or additive forms, but that it affords a higher degree of participation and the public becomes a direct partner in its development, as in the case of Sea Swim. By the same token, many of these formations will be unspectacular, embedded in the communities of which they are a part, and likely to attract relatively modest publicity. However, they may still have profound impacts, and provide a seed bed in which to nurture new genres - and because they create spaces of emergence - new sites of discovery.

A further analogy with sci-art is that art-sport collaborations have the problem of evolving not only novel ways of working, but also representations of what they are producing out of their mutual influence. Elsewhere, with colleagues who work in the transdisciplinary arena of sci-art, I have argued for the necessity of 'third spaces'; essentially, curated epistemic spaces 
where new knowledge arises (Muller et al 2015, Muller et al 2017, forthcoming). In the case of art-sport this is experiential knowledge of the body in movement. The Visual Matrix method was developed by Froggett et al (2015) specifically to respond to the gap in visual, sensory and kinaesthetic group based methodologies available to capture such experience, particularly in its aesthetic and affective dimensions. It has been successfully used in the field of Sci-Art to respond to emergent experience in third space where there is no existing discourse with which to articulate the new knowledge that emerges in the encounter between disciplines (Muller et al 2015, Muller et al 2017 forthcoming). There is considerable scope to apply it in art-sport contexts. As a method it aims to be 'experience near' (Geertz 1974) and depends on group-based associative thinking in response to a sensory or kinaesthetic stimulus (such as that provided in any of the examples described here) rather than analysis and opinion after the event. Critically, the visual matrix itself provides a third space in which experience is partially re-enacted and shared with others. The process is audio-recorded for later hermeneutic interpretation in a specially designed panel based process (Froggett et al 2015).

\section{The Conditions of Art-Sport: Participation in Third Space}




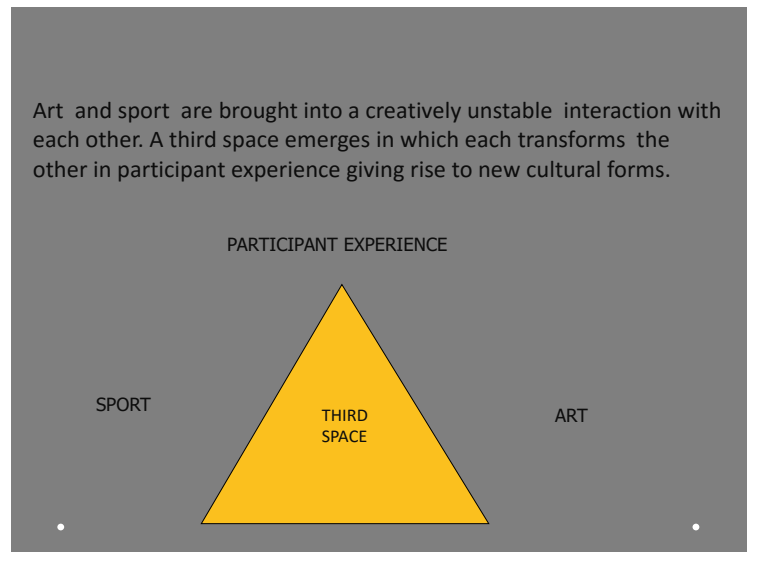

\section{Figure 9. The Third Space of Art-Sport}

The particular inventive freedom that a third space confers arises from the fact that it is a space apart from existing disciplines and practices, a social, relational and intrinsically ludic space established so that new encounters and discoveries can take place. It is created physically in a setting, as well as psychologically in the mind. What happens within it is, initially at least, open, undefined, and unbounded by rules, although new conventions may evolve as a distinctive form of practice develops. Sea Swim depended in just such a space, intuitively facilitated by its co-directors in such a way as to keep open the ways and means to represent the swimming as an aesthetic practice - an affective, physical, lyrical and, for some, spiritual experience. The protective comfort of beach huts was essential to holding this space as was the sense of community forged in the group as a whole. Out of this it became possible to swim in the liminal space of the sea and find there a basis for a new form of bodily self-expression: the art of swimming and swimming as art.

What has been offered in this article is a specific case-based set of responses to the questions asked at the beginning. There are numerous ways in which art and sport can intertwine and 
the additive, interactive, transformative typology is a relatively crude instrument to impose on a field that is perhaps best characterised as one of 'creative chaos'. Nothing would be gained by shoehorning these hybrid forms into a schema that imposes more organisation than reality will bear. However, its virtue as a heuristic device has been to throw into relief the essential role of audience engagement and participation in developing the possibilities and impacts of art-sport collaborations. If participants in the most radical, transformative model are to be taken seriously as co-producers of art-sport, then it needs to be understood in its complexity, not through schema that deconstruct experience into aesthetic, affective and physical dimensions but as a bio-psycho-cultural practice, with methods that are adequate for this purpose. Attention needs to be paid to the third space in which the intricate relationships that compose it can develop optimally. Creating these conditions demands a mind-set and skill that is learnt on the ground and that will only develop as collaborations mature, but there is a great deal to be gained from a strong philosophical standpoint that licences the transgression of boundaries between art and sport, and understands how these are underwritten by mind-body dualism. The Legacy Trust UK's assessment of the regional programmes it funded recognised the difficulty of working with these perspectives and concluded that other programmes had formulated simpler objectives and deliverables and therefore got off to a smoother start, but then struggled to identify what it all amounted to afterwards. Based on the fact that two of the examples discussed here have proved to be sustainable projects attracting continued participation, support and funding, it appears that at least in these instances imove's approach engendered a sense of direction for the longer term.

\section{References}

1. Best, D. 1974. “The Aesthetic in Sport.” British Journal of Aesthetics. 14: 197-213. 
2. Best, D. 1980. Art and Sport: Understanding the Value of Arts and Culture. Arts and Humanities Research Council, UK.

3. Bollas, C. 1992. Being a Character: Psychoanalysis and Self Experience. London: Routledge.

4. De Coubertain, P. 1988. L'Education en Angleterre. Paris: Hachette.

5. Froggett, L., Manley, J., Roy, A. and Hacking, S. 2013. Evaluation of the imove Programme: Yorkshire and Humber Cultural Olympiad Programme. Final Report, CLOK: University of Central Lancashire Research Repository http://clok.uclan.ac.uk/19648/1/imoveFINAL WORD 300713 071013.pdf

6. Froggett, L., Manley, J. and Roy, A. 2015. “The Visual Matrix Method: Imagery and Affect in a Group-based research setting” Forum Qualitative Sozialforschung / Forum: Qualitative Social Research, 16: (3) Art 6 http://www.qualitativeresearch.net/index.php/fqs/article/view/2308

7. Froggett, L. and Trustram, M. 2014. "Object relations in the museum: a psychosocial perspective". Museum Management and Curatorship, 29: (5) 482-497.

8. Gordzeijko, T. 2013. Create the Physical: imove and the art of human movement in eds. D. Sandle, J. Long, J. Parry, K. Spracklen (eds) Fields of Vision: the Arts in Sport, Leisure Studies Association, 126, pp.163-174. Eastbourne: University of Brighton. 
9. Gordzeijko, T. 2014. "The London 2012 Olympic Legacy and the wonder factor: implications for culture and the intrinsic versus instrumental debate". Journal of Policy Research in Tourism, Leisure and Events 6: (1) 80-84.

10. Langer, S. 1942, 1990. Philosophy in a New Key: A Study in the Symbolism of Reason, Rite, and Art. Cambridge, MA: Harvard University Press.

11. Lorenzer, A. 1986. Tiefenhermeneutische Kulturanalyse. In: A. Lorenzer, (ed.) Kultur-Analysen: Psychoanalytische Studien zur Kultur. Frankfurt/M.: Fischer, pp. $11-98$.

12. Lorenzer, A. and Orban, P. 1978. "Transitional objects and phenomena: Socialization and symbolisation", in S. Grolnick, L. Barkin \& W. Muensterberger (Eds.), Between reality and fantasy pp.471-482. New York: Jason Aronson.

13. Garcia, B. 2013. London 2012, Cultural Olympiad Evaluation. Liverpool: Institute of Cultural Capital. http://iccliverpool.ac.uk/wpcontent/uploads/2014/04/Garcia2013London2012COEvaluation-Summary.pdf

14. Geertz, C. 1974. From the Native's Point of View: On the nature of anthropological understanding. Bulletin of the American Academy of Arts and Sciences 28 (1): 26-45.

15. Holden, J. 2004. Capturing Cultural Value: how culture has become a tool of government policy. London: Demos.

16. Holden, J. 2006. Cultural Value and the Crisis of Legitimacy. London: Demos. 
Muller, L., Bennett, J., Froggett, L., and Bartlett, V. 2015. “Understanding Third Space: Evaluating art-science collaboration" in Proceedings of 21st International Symposium of Electronic Art, August 14th-18th 2015, Vancouver, Canada. (Archived CLOK: University of Central Lancashire Research Repository) http://clok.uclan.ac.uk/12024/1/12024_froggett_ISEA2015_submission_332.pdf

17. Muller, L., Froggett, L. and Bennett, J. Forthcoming, 2018. Emergent Knowledge in the Third Space of Art-Science.

18. Muller, N. (ed.) 2000. Pierre de Coubertain: Selected Writings. Lausanne: IOC.

19. O’ Brien, D. 2013. Cultural Policy: Management, Value and Modernity in the Creative Industries. London: Routledge.

20. Roberts, G. (ed.) 2011. Runs on the Board: an artists' celebration of over 50 's cricket in Yorkshire. Wakefield: RKL consultants.

21. Wedgwood-Clarke, J. 2014. Sea Swim. Scarborough: Valley Press.

22. Welsch, W. 2006. "Sport viewed aesthetically - and even as art”. Filosovski Vestnik online/Open Humanities Press.

https://ojs.zrc-sazu.si/filozofski-vestnik/article/viewFile/4076/3783 (accessed 21-0817).

23. Werz, S. 1986. "Representation and Expression in Sport and Art" Journal of the Philosophy of Sport 12: (1) 8-24. 
24. Winnicott, D. 1971, 2005. Playing and Reality. London: Routledge. 